\title{
The vibration health risk assessment on operators of different capacity dumpers at opencast mine in India
}

\author{
R. Kaviraj ${ }^{1}$, L. A. Kumaraswamidhas ${ }^{2}$ \\ Department of Mining Machinery Engineering, Indian Institute of Technology (ISM), \\ Dhanbad, Jharkhand, India \\ ${ }^{1}$ Corresponding author \\ E-mail: ${ }^{1}$ rkaviraj25@gmail.com, ${ }^{2}$ lakdhas1978@iitism.ac.in
}

Received 3 November 2018; accepted 13 November 2018

DOI https://doi.org/10.21595/vp.2018.20372

Check for updates

Copyright $(C) 18$ R. Kaviraj, et al. This is an open access article distributed under the Creative Commons Attribution License, which permits unrestricted use, distribution, and reproduction in any medium, provided the original work is properly cited.

\begin{abstract}
In a labour intensive sector, some of the factors in the work environment which impact the health of vehicle operators include: Whole-Body Vibration (WBV) and Hand-Arm Vibration (HAV). The vibrations transferred from the dumpers are harmful to the operators; hence a study was carried out to measure the vibration from dumpers and its effect on operators in Indian opencast mines. Dumper is a vehicle designed to transport bulk material and used extensively in the construction and mining industries. For the measurement, dumpers with the different capacities were selected from the opencast mines. Vibration measurements were carried out in accordance with ISO 5349-1 for the measurement of HAV and ISO 2631-1 for the measurement of WBV. The obtained WBV exposure result shows that the problem of musculoskeletal disorder was significantly higher with respect to $\operatorname{VDV}(8)(69 \%)$ in the exposed population as compared to $\mathrm{A}(8)$ r.m.s. acceleration (46\%). Moreover different capacity dumper vehicle hand transmitted vibration through steering wheel, $\mathrm{A}(8)$ r.m.s. acceleration observed in the range of $1.91 \mathrm{~m} / \mathrm{s}^{2}-4.28 \mathrm{~m} / \mathrm{s}^{2}$. As per EU DIRECTIVE 2002/44/EC, specified Exposure Action Value (EAV) $71 \%$ measured A(8) value falls within EAV limit. However, despite of the result operator experience problem of hand arm vibration syndrome. Hence there is a need of ergonometric deign enhancement on dumpers vehicle's seat and steering wheel.
\end{abstract}

Keywords: dumper, whole-body vibration, hand-am vibration, low back pain, arm pain.

\section{Introduction}

Ever increasing demand for energy resources in India warrants for productivity enhancement in the mining sector. This often results in prolonged working hours for operators of machines and equipment's causes health-related issues due to whole body vibration (WBV) and Hand Arm Vibration (HAV). The heavy earth moving equipment operators in the mining operations are exposed to significant higher level of vibration and shocks for an extended period of time. These vibrations are harmful and cause discomfort for the operators. Across the world, numerous epidemiological studies were carried out and documented the effects of high vibration exposure among the operators of Load haul dumper, Front end loader, Dozer, Excavator and Dumper [1-5]. In this regard many international standards have been established to investigate the occupational health and safety issues to regulate the human vibration measurement procedure and reporting. Among these, ISO 2631-1 (1997) [6] and ISO-5349-1 are well known measurement procedures for WBV and HAV [7] measurements respectively. Dumpers are mainly used for transportation of minerals, coals and other bulk materials in the mining and construction industries. In the mining industry, dumpers are used extensively throughout the day without stoppage; hence there is a strong need to reduce vibration exposure on the operators. Past studies revealed that WBV exposure is influenced by vehicle maintenance, age of the vehicle, vehicle capacity; design of seat suspension and terrain profile [8-11].

In South Wales, Wolfgang and Burgess-Limerick [12] measured WBV from dumpers with the capacity ranging from 136 ton to 290 ton, r.m.s. acceleration in the range of $0.27 \mathrm{~m} / \mathrm{s}^{2}$ to $0.74 \mathrm{~m} / \mathrm{s}^{2}$. Similar study was conducted by Kumar [13] where the dumper's capacity ranged from 240 ton to 
320 ton observed greatest mean weighted r.m.s. acceleration in the range of $0.37 \mathrm{~m} / \mathrm{s}^{2}$ to $11.73 \mathrm{~m} / \mathrm{s}^{2}$. On the aspect of topography in Netherlands mines, Noorloos [14] measured WBV amplitudes associated with a range of mining equipment's including dumper observed mean weighted r.m.s. acceleration $0.42 \mathrm{~m} / \mathrm{s}^{2}$. In Contrast A. P. Vanerkar [3] conducted WBV study on metalliferous mines i.e., Bauxite, and Iron ore mines with four different HEMM vehicles which include dumper, Dozer, Shovel, and Drill. The study results indicated that there is no significant effect on the type of mine but are dependent on the working condition and type of HEMM employed in operation. However, as far as author's knowledge concern, there are no studies have been done to assess the HAV exposure on hand-arm through steering wheel to the operator during dumper operation. This type of HAV exposure negatively impacts the productivity and efficiency of the operator.

In this respect, the present study investigates the relationship between induced vibration levels from different capacity dumper in Indian terrain. Based on vibration severity useful recommendations for dumper operator are suggested.

\section{Method}

\subsection{Selection of vehicles}

The study was conducted in Indian mines where dumpers are used to transport ore and overburden. The measurements were taken using seven dumpers with the capacities ranging from 35 ton, 60 ton and 100 ton. Selection of vehicle was based on availability and vehicle condition on the aspect of maintenance frequency. In this study the dumpers were selected with minimum maintenance frequency of 3 in a year. Vehicle design features are presented in Table 1.

Table 1. Specification and vehicle history

\begin{tabular}{|c|c|c|c|c|c|}
\hline Vehicle & $\begin{array}{c}\text { Capacity } \\
\text { (ton) }\end{array}$ & $\begin{array}{c}\text { Maintenance } \\
\text { frequency/year }\end{array}$ & $\begin{array}{c}\text { Vehicle age } \\
\text { (year) }\end{array}$ & $\begin{array}{c}\text { Max. working } \\
\text { hours/day }\end{array}$ & $\begin{array}{c}\text { Material } \\
\text { handled }\end{array}$ \\
\hline Dumper \#1 & 35 & 6 & 3 & 14 & Mineral/Overburden \\
\hline Dumper \#2 & 35 & 5 & 5 & 9 & Mineral/Overburden \\
\hline Dumper \#3 & 35 & 6 & 6 & 12 & Mineral/Overburden \\
\hline Dumper \#4 & 60 & 4 & 5 & 10 & Mineral/Overburden \\
\hline Dumper \#5 & 60 & 3 & 2 & 9 & Mineral/Overburden \\
\hline Dumper \#6 & 100 & 7 & 6 & 13 & Mineral/Overburden \\
\hline Dumper \#7 & 100 & 3 & 2 & 9 & Mineral/Overburden \\
\hline
\end{tabular}

\subsection{Selection of vehicle operators}

Five dumper operators (all male) who volunteered to participate with mean age of 33 years, average work experience of about 7.6 years and mean mass of $69 \mathrm{~kg}$, and average height $1.69 \mathrm{~m}$ were taken for the study. Operators were also given with a questionnaire to gather information on work experience and health-related history related to vehicle operation and it is reported in Table 2.

\subsection{Measurement device}

The WBV was measured in accordance with ISO 2631-1 at the operator/ seat interface using the accelerometer mounted in a rubber seat pad. Moreover, the HAV was measured in accordance with ISO 5349-1 at operator/steering wheel interface. The human vibration analyzer type 4447 measures vibration in three perpendicular axes, manufactured by Bruel and Kjaer was used for the analysis. Vibration exposure levels under typical operating conditions for each vehicle were measured. Several repeated measurements were performed for each vehicle and subsequently averaged in an effort to obtain a representative sample. 
THE EFFECT VIBRATION ON OPERATORS WITH A DIFFERENT CAPACITY DUMPER AT OPENCAST MINE IN INDIA.

R. KAVIRAJ, L. A. KUMARASWAMIDHAS

Table 2. Vehicle operator anthropometric data along with self-reported health issues

\begin{tabular}{|l|c|c|c|c|c|c|c|c|}
\hline Operator & \multirow{2}{*}{$\begin{array}{c}\text { Age } \\
\text { (year) }\end{array}$} & \multirow{2}{*}{$\begin{array}{c}\mathrm{BMI} \\
\left(\mathrm{kg} / \mathrm{m}^{2}\right)\end{array}$} & \multirow{2}{*}{$\begin{array}{c}\text { Experience } \\
\text { (year) }\end{array}$} & $\begin{array}{c}\text { Daily work } \\
\text { limit (hour) }\end{array}$ & $\begin{array}{c}\text { Low back } \\
\text { pain }\end{array}$ & Arm pain & $\begin{array}{c}\text { Finger } \\
\text { pain }\end{array}$ & $\begin{array}{c}\text { Upper back } \\
\text { pain }\end{array}$ \\
\hline Operator \#1 & 29 & 24 & 6 & 8 to $10 \mathrm{hr}$ & 3 & 2 & 2 & 2 \\
\hline Operator \#2 & 33 & 23 & 9 & 8 to $10 \mathrm{hr}$ & 4 & 1 & 3 & 3 \\
\hline Operator \#3 & 36 & 25 & 8 & 8 to $10 \mathrm{hr}$ & 3 & 1 & 2 & 2 \\
\hline Operator \#4 & 42 & 28 & 12 & 8 to $10 \mathrm{hr}$ & 3 & 3 & 2 & 1 \\
\hline Operator \#5 & 26 & 22 & 3 & 8 to $10 \mathrm{hr}$ & 2 & 1 & 1 & 1 \\
\hline
\end{tabular}

\subsection{Measurement collection procedures}

The dumpers are operated in different designated work areas at least for an 8-hour in each site. They are involved in a cyclic process like loading, loaded travel, dumping and empty travel. The cycle time of dumper varies, depends upon the mine layout, development heading, road gradient, dumping zone and sharp turns. Most dumper vehicle operator usually take 7-20 min to complete one cycle, depends on various conditions. The number of work cycle completed in 1-hour is typically ranged from 3-8 cycles.

\section{Results and discussion}

\subsection{Effect of WBV exposure on dumper}

In this work across different capacity dumper vehicles, changes in WBV at three different vibration source i.e., seat pan, backrest and floor transmitted vibration to the operator were measured. Frequency-weighted r.m.s accelerations and VDV were measured and obtained result normalized to 8-hour working conditions as summarized in Table 3. Operators health risk evaluation as per ISO 2631-1 [6] suggests that the dominant axis method is acceptable unless two or more axes are of similar magnitude where the multi-axis vector sum is recommended. In this investigation dominant VDV acceleration occurred in the $z$-axis with operator seat and in the $x$-axis with the backrest of the dumper vehicles.

The reported VDV acceleration at operator seat pan interface are in agreement with the earlier research findings [12-16]. In the current study, measured VDV acceleration maximum in the $Z$-axis for the combined tasks i.e., during loading, loaded travel, dumping, and empty travel. The measured $\operatorname{VDV}(8)$ acceleration at seat pan was found to be in the range of $12.02-24.27 \mathrm{~m} / \mathrm{s}^{1.75}$ (Table 3).

Operator experience WBV at seat backrest tends to exhibit slightly lower vibration compared to seat pan. However, maximum VDV acceleration is observed in the $x$-axis i.e., fore-and-aft direction in the range of $15.98-27.36 \mathrm{~m} / \mathrm{s}^{1.75}$. As can be seen VDVs are calculated from the fourth power of the acceleration time history making them more sensitive to shocks/peaks than the frequency-weighted r.m.s. method that uses the second power as average acceleration [6]. This study also compares measure of $\operatorname{VDV}(8)$ and $\mathrm{A}(8)$ acceleration health risk probability in different capacity dumper as shown in Fig. 1. Based on the calculated VDV(8) values $69 \%$ of the measured data were above the Health Guidance Caution Zone (HGCZ), when the A(8) values were considered $46 \%$ were above the HGCZ observed at operator seat pan interface (Fig. 1(a)). Moreover, with respect to capacity 60-ton dumper observed dominant axis (i.e., $Z$-axis) vibration levels within HGCZ limits at operator seat interface. In Contrast, operator experience high magnitude of acceleration in fore-and-aft direction (i.e., $x$-axis), and observed acceleration values above the upper limit of the HGCZ as per ISO 2631-1 (Fig. 1(b)). Furthermore, highest magnitude of acceleration observed at floor with all capacity dumpers (Fig. 1(c)).

Vibration exposure experienced by dumper operator is a component of various factors: vehicle design, speed, capacity, suspension system, maintenance frequency, seat design and operator's 
vehicle operational skill. Operators drive their vehicle substantially quicker while coming back with the unfilled truck than a stacked truck. Kumar [11] also noted that vibration levels particularly high when empty travel, in contrast to the loaded dumper travel. However, in loaded truck increases in WBV is due to the non-uniform mass distribution of transport materials. A coupled vibration impact causes a lot of discomfort to the operator throughout the performance of the operation cycle.

Table 3. Mean (standard deviation) acceleration value of the A(8) and $\operatorname{VDV}(8)$ on dumper

\begin{tabular}{|c|c|c|c|c|c|c|c|}
\hline \multirow{2}{*}{ Capacity } & & \multicolumn{2}{|r|}{ Floor } & \multicolumn{2}{|c|}{ Seat pan } & \multicolumn{2}{|c|}{ Backrest } \\
\hline & & $\mathrm{A}(8)\left(\mathrm{m} / \mathrm{s}^{2}\right)$ & $\operatorname{VDV}(8)\left(\mathrm{m} / \mathrm{s}^{1.75}\right)$ & $\mathrm{A}(8)\left(\mathrm{m} / \mathrm{s}^{2}\right)$ & $\operatorname{VDV}(8)\left(\mathrm{m} / \mathrm{s}^{1.75}\right.$ & $\mathrm{A}(8)\left(\mathrm{m} / \mathrm{s}^{2}\right)$ & $\operatorname{VDV}(8)\left(\mathrm{m} / \mathrm{s}^{1.75}\right.$ \\
\hline \multirow{3}{*}{$\begin{array}{c}35 \text { Ton } \\
(n=15)\end{array}$} & $x$ & $0.78( \pm 0.11)$ & $15.93( \pm 1.52)$ & $0.63( \pm 0.06)$ & & & \\
\hline & $y$ & & $2( \pm 1.83)$ & 0.28( & & & \\
\hline & $Z$ & 1.1 & & 0.84 & & & \\
\hline \multirow{3}{*}{$\begin{array}{c}60 \text { Ton } \\
(n=10)\end{array}$} & $x$ & & & & & & \\
\hline & $y$ & 0.5 & & & & & \\
\hline & $Z$ & 1.00 & & & & 0.31 & \\
\hline \multirow{3}{*}{$\begin{array}{l}100 \text { Ton } \\
(n=10)\end{array}$} & $x$ & $1.03( \pm 0.15)$ & & 0.67 & & $1.38( \pm 0.23)$ & 4.03) \\
\hline & $y$ & $0.53( \pm 0.07)$ & 17.54( & $0.43( \pm 0.23)$ & $13.69( \pm 0.89)$ & $0.41( \pm 0.07)$ & $\pm 0.91)$ \\
\hline & $Z$ & $0.86( \pm 0.13)$ & $23.11( \pm 1.43)$ & $1.12( \pm 0.24)$ & $24.27( \pm 4.52)$ & $0.55( \pm 0.33)$ & $11.21( \pm 1.43)$ \\
\hline
\end{tabular}

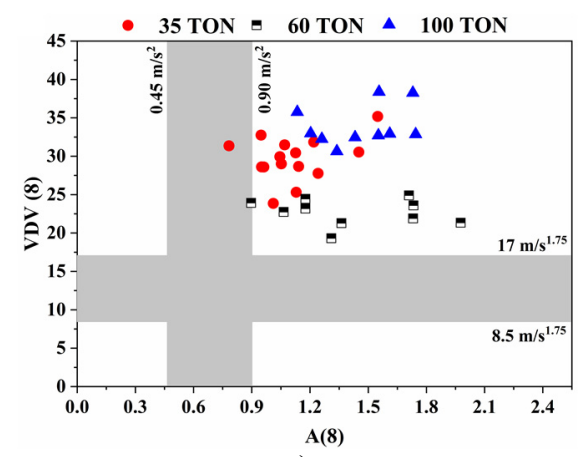

a)

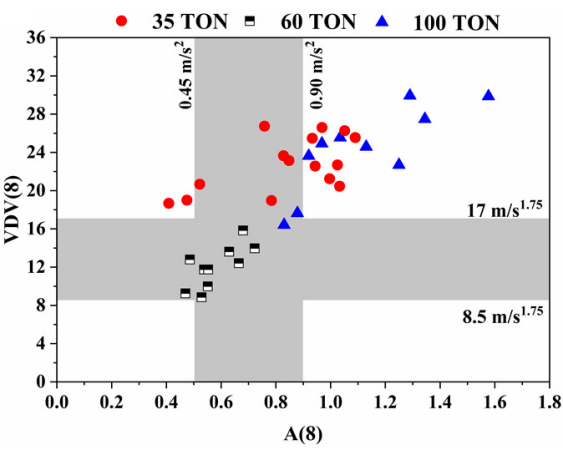

b)

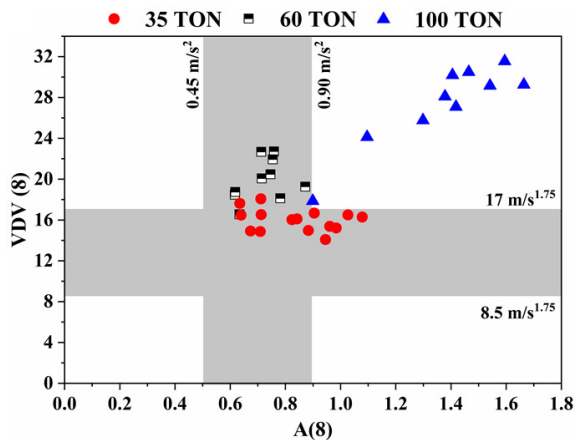

c)

Fig. 1. A(8) versus VDV(8) WBV scatter plot of dumper at 3 different location: a) floor, b) seat pan, and c) backrest

\subsection{Effect of HAV exposure on dumper}

The potential health injuries associated with human hand-transmitted mechanical vibration which caused during dumper vehicle driving. During different capacity dumpers vehicle operation steering wheel induced maximum HAV exposure in $z$-axis with 35 ton and 100 ton dumper. As shown in Fig. 2(a). The observed r.m.s. acceleration ranged between $0.38 \mathrm{~m} / \mathrm{s}^{2}-3.26 \mathrm{~m} / \mathrm{s}^{2}$. As per 
EU DIRECTIVE 2002/44/EC recommended action limit is $2.5 \mathrm{~m} / \mathrm{s}^{2}-5 \mathrm{~m} / \mathrm{s}^{2}$ is not harmful to the operator [17]. Furthermore as per ISO 5349-1 standard recommend vibration total value for the assessment of HAV to calculate daily exposure vibration exposure $\mathrm{A}(8)$ acceleration values [7]. As shown in Fig. 2(b), measured A(8) acceleration values ranged between $1.91 \mathrm{~m} / \mathrm{s}^{2}-4.28 \mathrm{~m} / \mathrm{s}^{2}$. An observed value also lies within recommended EU DIRECTIVE 2002/44/EC values. However, operator feedback results showed a prevalence of persistent hand numbness and loss of sensation in fingers due to prolonged HAV exposure.

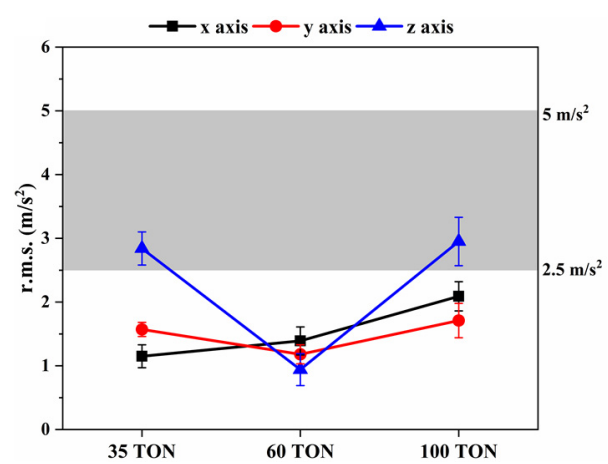

a)

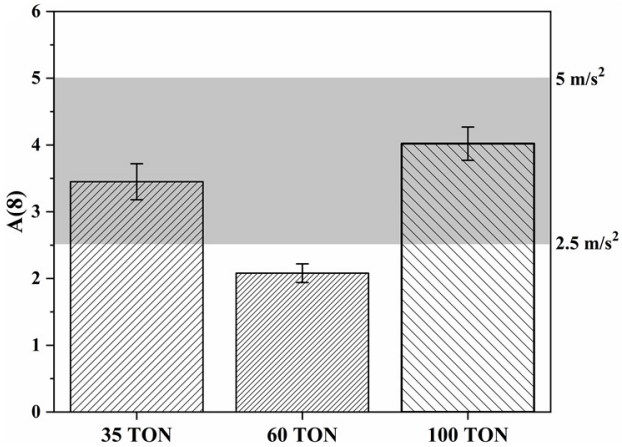

b)

Fig. 2. HAV exposure at steering wheel with different capacity of dumper: a) three different axis r.m.s. acceleration, b) A(8) acceleration

\section{Conclusions}

The operators undertaken for the study registered WBV levels across different capacity dumpers were above and within the HGCZ limit as per ISO 2631-1 standard. The assertive vibration magnitude will increase the chance of semi-permanent health effects and decreases operator's efficiency in a work shift. Conversely, registered HAV exposure level within the recommended action limit. Despite, the fact that operator encounters torment in arm, numbness and loss of sensation. This ascertained results of HAV and WBV suggests, a dire need design improvement of seat, and steering wheel. This ergonometric design enhancement will help to increase in operator comfort operation.

\section{References}

[1] Mayton A. G., Jobes C. C., Gallagher S. Assessment of whole-body vibration exposures and influencing factors for quarry haul truck drivers and loader operators. International Journal of Heavy Vehicle Systems, Vol. 21, 2014, p. 241-261.

[2] Burgess-Limerick Robin, Lynas Danellie Long duration measurements of whole-body vibration exposures associated with surface coal mining equipment compared to previous short-duration measurements. Journal of Occupational and Environmental Hygiene, Vol. 13, 2016, p. 339-345.

[3] Vanerkar A. P., Kulkarni N. P., Zade P. D., Kamavisdar A. S. Whole body vibration exposure in heavy earth moving machinery operators of metalliferous mines. Environment Monitoring Assess, Vol. 143, 2008, p. 239-245.

[4] Burstrom Lage, Hyvarinen Ville, Johnsen Magnar, Pettersson Hans Exposure to whole-body vibration in open-cast mines in the Barents region. International Journal of Circumpolar Health, 75, p. 2016-29373.

[5] Eger T., Stevenson J. M., Grenier S., Boileau P. E., Smets M. P. Influence of vehicle size, haulage capacity and ride control on vibration exposure and predicted health risks for LHD vehicle operators. Journal of Low Frequency Noise, Vibration and Active Control, Vol. 30, 2011, p. 45-62.

[6] ISO 2631-1: 1997. Mechanical Vibration and Shock: Evaluation of Human Exposure to Whole-body Vibration. Part 1, General Requirements. International Organization for Standardization, 1997. 
[7] ISO 5349: 2001. Mechanical Vibration - Guidelines for the Measurement and Evaluation of Human Exposure to Hand Transmitted Vibration. Part 1, General Requirements. International Organization for Standardization, Switzerland, 2001.

[8] Marin L. S., Rodriguez A., Rey E., Barrero L. H., Dennerlein J., Johnson P. W. Influence of speed in whole body vibration exposure in heavy equipment mining vehicles. Proceedings of the Human Factors and Ergonomics Society 2016 Annual Meeting, Vol. 60, 2016, p. 919-922.

[9] Shamsul Akmar Ab Aziz, Mohd Zaki Nuawi, Jailani Mohd Nor Predicting whole body vibration (WBV) exposure of Malaysian Army three-tonne truck drivers using integrated kurtosis-based algorithm for Z-notch filter technique 3D (I-kaz 3D). International Journal of Industrial Ergonomics, Vol. 52, 2016, p. 59-68.

[10] Donati P. Survey of technical preventative measures to reduce whole-body vibration effects when designing mobile machinery. Journal of Sound and Vibration, Vol. 253, 2002, p. 169-183.

[11] Velmurugan P., Kumaraswamidhas L. A., Sankaranarayanasamy K. Influence of road surfaces on whole body vibration for suspended cabin tractor semitrailer drivers. Journal of Low Frequency Noise, Vibration and Active Control, Vol. 31, 2012, p. 75-84.

[12] Wolfgang R., Burgess-Limerick R. Whole-body vibration exposure of haul truck drivers at a surface coal mine. Applied Ergonomics, Vol. 45, 2014, p. 1700-1704.

[13] Kumar S. Vibration in operating heavy haul trucks in overburden mining. Applied Ergonomics, Vol. 35, 2004, p. 509-520.

[14] Noorloos D., Tersteeg L., Tiemessen I. J., Hulshof C. T., Frings Dresen M. H. Does body mass index increase the risk of low back pain in a population exposed to whole body vibration. Applied Ergonomics, Vol. 39, 2008, p. 779-785.

[15] Smets M. P. H., Eger T. R., Grenier S. G. Whole-body vibration experienced by haulage truck operators in surface mining operations: A comparison of various analysis methods utilized in the prediction of health risks. Applied Ergonomics, Vol. 41, 2010, p. 763-770.

[16] Mandal B. B., Srivastava A. K. Musculoskeletal disorders in dumper operators exposed to whole body vibration at Indian mines. International Journal of Mining, Reclamation and Environment, Vol. 24, 2010, p. 233-243.

[17] The European Parliament and the Council of the European Union Directive 2002/44/EC of the European parliament and of the Council of 25 June 2002 on the minimum health and safety requirements regarding the exposure of workers to the risks arising from physical agents (vibration) (16th individual Directive within the meaning of Article 16 (1) of Directive 89/391/EEC). Official Journal of the European Communities, 2002. 